\title{
Immunosuppression Induced by HIV Infection
}

Mohamed G Elfaki*

Department of Infection and Immunity, King Faisal Specialist Hospital and Research Centre and Alfaisal University College of Medicine, Riyadh, Saudi Arabia

${ }^{*}$ Corresponding author: Mohamed G Elfaki, Department of Infection and Immunity, King Faisal Specialist Hospital \& Research Centre, P.O. Box 3354, MBC 03, Riyadh 11211, Kingdom of Saudi Arabia, Tel: +966546271771; Fax: +9660114424519; E-mail: elfaki@kfshrc.edu.sa

Received date: July 17, 2014, Accepted date: August 20, 2014, Published date: August 27, 2014

Copyright: (c) 2014 M.G. Elfaki, et al. This is an open-access article distributed under the terms of the Creative Commons Attribution License, which permits unrestricted use, distribution, and reproduction in any medium, provided the original author and source are credited.

\begin{abstract}
Immunosuppression due to HIV infection is a resultant of several factors including defective innate signaling pathways, increased viral replication and virus load, gradual loss of peripheral $\mathrm{CD}^{+} \mathrm{T}$ cells and depletion of $\mathrm{T}$ lymphocytes at mucosal sites that collectively lead to progressive immune deficiency and AIDS development. T cells derived from HIV patients were anergic and failed to mount a robust adaptive immune response. The host, on the other hand, becomes vulnerable to opportunistic infections such as tuberculosis and AIDS-related cancer such as Kaposi sarcoma, non-Hodgkin lymphoma, and cervical cancer with remarkable level of immunosuppression. Elucidation of the various mechanisms involved in these immunologic perturbations is necessary to understand HIV pathogenesis for an effective immunotherapy.
\end{abstract}

Keywords: HIV pathogenesis; Immune activation

\section{Background and Significance}

Infection with human immunodeficiency virus (HIV) has been identified as a causal agent of AIDS, a pandemic disease that constitutes a global public health threat for the past 3 decades [1]. It is well established that HIV preferentially infects lymphocytes with consequent depletion of CD4 $4^{+}$lymphocytes at mucosal sites [2,3]. The progressive death of $\mathrm{T}$ lymphocytes is attributed to immune activation rather than to viral cytopathic effect. The resulting immune dysfunction in HIV patients is likely due to combinatorial effects resulting from infection of immune cells $\left(\mathrm{CD} 4^{+} \mathrm{T}\right.$ cells, macrophages, dendritic cells) with HIV, uncontrolled viral replication that impairs antigen presentation, increased mutations in env protein gp120 that leads to virus tropism and survival, increased activation of $\mathrm{T}$ helper cells by alloantigens, increased apoptosis by activated $\mathrm{CD} 4^{+} \mathrm{T}$ helper cells, down-regulation of $\mathrm{CD}^{+}{ }^{+}$synthesis with functional impairment, and perturbation of cytokine pathways [4-6]. The sequel of these effects renders the patients immunosuppressed and vulnerable to opportunistic infections with consequent death. Among the common opportunistic disorders encountered in HIV patients, tuberculosis and AIDS-related cancer such as Kaposi sarcoma, non-Hodgkin lymphoma and cervical cancer.

However, these immunologic defects can be partially restored in HIV patients treated with highly active antiretroviral therapy (HAART) [7]. Patients who accessed HAART treatment and adhered to its regimen had shown significant reduction in AIDS-related mortality and high prevalence of comorbidities due to cardiovascular disease, diabetes, and non-AIDS cancers [8]. Thus, HIV is a relentlessly progressive disease and difficult to cure with HAART due to the persistence of HIV-1 virus in latent reservoirs that may lead to viral remission and development of AIDS [9]. The progression of HIV disease in HAART-treated patients can be virtually monitored by evaluation of inflammatory markers (e.g. kynurenines, Kyn) and Th17/Treg balance in HIV progressors $[10,11]$. Despite the functional improvement in HAART-treated patients, as evidenced by reduced viral load and improved $\mathrm{CD} 4^{+} \mathrm{T}$ cells count, a paradoxical response known as immune reconstitution inflammatory syndrome (IRIS) has evolved [12]. The induction of IRIS is worsened in HIV patients with preexisting opportunistic infections. In general, the severity of IRIS depends on $\mathrm{CD}^{+} \mathrm{T}$ cells count $(\leq 100-200$ cells/ $\mu \mathrm{l})$, degree of lymphocyte apoptosis or proliferation, and the degree of viral suppression and immune recovery after the initiation of treatment with HAART.

Furthermore, the status of immunosuppression is complicated by increased HIV mutations and genetic diversity during virus replication, ability of the virus to establish a pool of latently infected $\mathrm{CD} 4^{+} \mathrm{T}$ cells during early stage of infection, failure of neutralizing antibodies to eliminate HIV replication, and failure of viral antigens to induce an effective T cell memory [13-18]. All of these factors lead the virus to evade the immune system with consequent failure of immune control. Therefore, development of an effective HIV vaccine remains elusive [13] unless obstacles pertaining to the virus and the host are defined for successful discovery of vaccine targets. In the era of omics technologies [19], application of high-throughput methods for vaccine discovery is promising to resolve the above hurdles and might be helpful for better understanding of the immune response to HIV infection with consequent development of an effective vaccine for which conventional methods had failed. In light of these challenges, current efforts for vaccine discovery against HIV are focused on the identification of immunogens that elicit broadly neutralizing antibodies coupled with the induction of HIV-specific cytotoxic T lymphocytes [13].

\section{Conclusion:}

In conclusion, immunosuppression elicited by HIV infection is different from other microbial infections [20], and solely complicated to be unidirectionally manipulated. Elucidation of the mechanistic events involved in virus replication coupled with the incurred perturbations in the host innate and adaptive immune signaling pathways are of paramount importance to define HIV pathogenesis and immunity. 
Page 2 of 2

\section{References}

1. Miedema F, Tersmette M, Van Lier RA (1990) AIDS pathogenesis: dynamic interaction between HIV and the immune system. See comment in PubMed Commons below Immunol Today 11: 293-297.

2. Douek DC, Brenchley JM, Betts MR, Ambrozak DR, Hill BJ, et al. (2002) HIV preferentially infects HIV-specific CD4+T cells. See comment in PubMed Commons below Nature 417: 95-98.

3. Brenchley JM, Price DA, Douek DC (2006) HIV disease: fallout from a mucosal catastrophe? See comment in PubMed Commons below Nat Immunol 7: 235-239.

4. Brenchley JM, Price DA, Schacker TW, Asher TE, Silvestri G, et al. (2006) Microbial translocation is a cause of systemic immune activation in chronic HIV infection. See comment in PubMed Commons below Nat Med 12: 1365-1371.

5. Lyerly HK, Matthews TJ, Langlois AJ, Bolognesi DP, Weinhold KJ (1987) Human T-cell lymphotropic virus IIIB glycoprotein (gp120) bound to CD4 determinants on normal lymphocytes and expressed by infected cells serves as target for immune attack. Proc Natl Acad Sci U S A 84 4601-4605.

6. Trautmann L, Janbazian L, Chomont N, Said EA, Gimmig S, et al. (2006) Upregulation of PD-1 expression on HIV-specific CD8+ T cells leads to reversible immune dysfunction. Nat Med 12: 1198-1202.

7. French MA, Price P, Stone SF (2004) Immune restoration disease after antiretroviral therapy. AIDS 18: 1615-1627.

8. Deeks SG, Hunt PW (2014) Antiretroviral therapy: stubborn limitations persist. Lancet 384: 214-216.

9. Barouch DH, Deeks SG2 (2014) Immunologic strategies for HIV-1 remission and eradication. Science 345: 169-174.

10. Chen J, Shao J, Cai R, Shen Y, Zhang R, et al. (2014) Anti-retroviral therapy decreases but does not normalize indoleamine 2,3-dioxygenase activity in HIV-infected patients. PLoS One 9: e100446.
11. Jenabian MA, Patel M, Kema I, Kanagaratham C, Radzioch D, et al. (2013) Distinct tryptophan catabolism and Th17/Treg balance in HIV progressors and elite controllers. PLoS One 8: e78146.

12. Cheng VC, Yuen KY, Chan WM, Wong SS, Ma ES, et al. (2000) Immuno restitution disease involving the innate and adaptive response. Clin Infect Dis 30: 882-892.

13. Johnston MI, Fauci AS (2008) An HIV vaccine--challenges and prospects. N Engl J Med 359: 888-890.

14. Chun TW, Engel D, Berrey MM, Shea T, Corey L, et al. (1998) Early establishment of a pool of latently infected, resting CD4(+) T cells during primary HIV-1 infection. Proc Natl Acad Sci USA 95: 8869-8873.

15. Burton DR, Desrosiers RC, Doms RW, Koff WC, Kwong PD, et al. (2004) HIV vaccine design and the neutralizing antibody problem. Nat Immunol 5: 233-236.

16. Hazenberg MD, Hamann D, Schuitemaker H, Miedema F (2000) T cell depletion in HIV-1 infection: how CD4+T cells go out of stock. Nat Immunol 1: 285-289.

17. Burton DR, Weiss RA (2010) AIDS/HIV. A boost for HIV vaccine design. Science 329: 770-773.

18. McMichael AJ, Haynes BF (2012) Lessons learned from HIV-1 vaccine trials: new priorities and directions. Nat Immunol 13: 423-427.

19. He Y (2012) Omics-based systems vaccinology for vaccine target identification, Drug Dev. Res., 73: 559-568.

20. Elfaki MG, Al-Hokail AA, Kambal AM (2012) Microbial immunosuppression. In: Suman Kapur and Maristela B. Portela (eds) Immunosuppression-Role in Health and Diseases. InTech Publisher, Rijeka, Croatia. 